\title{
Fear of fatness and adolescent girls: implications for obesity prevention
}

\author{
BY MARY A. T. FLYNN \\ Department of Biological Sciences, Dublin Institute of Technology, Kevin Street, Dublin 8, \\ Republic of Ireland
}

Female adolescence is the phase of growth and development bridging childhood and womanhood; a physical transition necessitating unique social and psychological adjustment. In physical terms, growth during adolescence includes the development of the sexual organs to full reproductive function, and contributes to the average female adult approximately $15 \%$ of her height, $40 \%$ of her weight (Hoey et al. 1986) and $40 \%$ of her total bone mineral content (Matkovic, 1991). The start of adolescence is characterized by the pubertal growth spurt which in females is usually about 2 years earlier than in males, and represents one of the most rapid periods of growth experienced by women during their lifetime. Although the duration of the growth spurt is usually the same (3-4 years) the timing of its inception varies within each sex, usually occurring between the ages of 9 and 13 years in females. Consequently nutritional requirements during female adolescence correlate more closely with biological maturity than with chronological age.

To support this growth and development adolescent girls require diets of high nutritional quality and, thus, represent a nutritionally vulnerable group. Any event which carries additional nutritional costs, such as pregnancy, lactation, illness or participation in competitive sports, greatly increases their risks of dietary inadequacy. Similarly any event interfering with their food intake, such as dietary restraint associated with a fear of fatness, can also lead to malnutrition. Crawley \& Shergill-Bonner (1995) recently described how dieting 16-17-year-old British girls had significantly lower intakes of all micronutrients compared with girls who were not dieting. Apart from increased risks due to inadequate intakes of specific nutrients, for example of osteoporosis due to low $\mathrm{Ca}$ intakes (National Institutes of Health, 1994), it has been documented that such dietary restraint can lead to growth failure and delayed puberty (Pugliese et al. 1983). Although the long-term risks of growth failure during adolescence are largely unknown, it has been suggested that this may be linked with an increased mortality risk in girls (Nieto et al. 1992).

\section{FEAR OF FATNESS AMONG ADOLESCENT GIRLS}

Studies indicate that up to $70 \%$ of adolescent girls have attempted to lose weight (Moses $e t$ al. 1989; Wadden et al. 1989; Fox, 1991). In fact, body weight dissatisfaction arising from a fear of fatness is so pervasive among this group that it has been referred to as 'a normative discontent' (Wadden et al. 1989). Whilst avoidance of obesity is of itself recognized as a healthy practice, the inappropriate dieting and weight-loss behaviours known to accompany fear of fatness in adolescent girls may actually pose a far greater threat to their health than obesity.

The most popular slimming method used by this group is self-imposed dieting which, although more common in the overweight, is practised by normal and even very underweight girls (Wadden et al. 1989; Whitaker et al. 1989); and by those as young as 9 years of age (Maloney et al. 1989; Hill et al. 1994). Reports of weight loss achieved by adolescent dieters provide a crude description of the degree to which they actually achieve 
energy intake restriction. In a study involving 5108 American adolescents $5 \mathrm{~kg}$ was the maximum weight loss reported for female dieters, some of whom reported fasting completely (Whitaker et al. 1989); while the amount of weight lost by Irish adolescents reportedly ranged between 3 and $28 \mathrm{~kg}$ (Fox, 1991). The fact that $62 \%$ of the Irish girls reported regaining the weight they had lost lends some support to the suggestion that periods of dietary restraint may lead to episodes of excessive eating (Hill, 1993a). Apart from the potential of such dietary practices to interfere with growth and development (as discussed previously), these behaviours may be linked with the emergence of clinical eating disorders (Hill, 1993b).

In relation to this as many as $13 \%$ of 15 -year-old American adolescents have reported purging behaviour involving either self-induced vomiting, laxative or diuretic abuse with female purgers outnumbering male purgers by $2: 1$ (Killen et al. 1986). While the authors report that the frequency of purging for most in this study was 'too low to be considered pathologic', they considered that such behaviours were risk indicators for the development of eating disorders (Killen et al. 1986). A subsequent survey of anorexic and bulimic symptoms in a non-referred adolescent population confirmed that although many aspire to be thin, only a small minority report forms of weight control that are serious enough to fulfil the strict diagnostic criteria for anorexia nervosa or bulimia nervosa (Whitaker et al. 1989). These findings support the view that these clinical eating disorders are, in fact, relatively rare and are not on the increase. In relation to fear of fatness, however, there is growing agreement that anorexia and bulimia nervosa may only represent the severe end of the eating disorder spectrum, and that the milder variants of eating pathology are more highly prevalent among vulnerable groups such as adolescent girls (Lucas, 1983; Pugliese et al. 1983; Hill, 1993b). The issue of whether the widespread dieting practices associated with fear of fatness among adolescent girls contribute to the prevalence of cases of clinical eating disorders is debatable (Hill, 1993a,b). Nonetheless, the findings of a prospective study of London schoolgirls, in which the relative risk of dieters becoming cases with an eating disorder was eight times that of non-dieters (Patton et al. 1990), would appear to support some link between the two.

\section{'Fatness phobia; more harmful than obesity?'}

Preliminary results from an on-going study of Dublin schoolgirls (mean age 15 years, $n$ 420 ) provide a recent description of the fear of fatness phenomenon among adolescent girls (Ryan et al. 1997). In agreement with other studies (Wadden et al. 1989; Whitaker et al. 1989) a high level of dissatisfaction with body weight has been identified in this study where even the girls who described themselves as 'underweight' or 'normal weight' were slimming (Ryan et al. 1997). While dieting and exercise represented the most-commonlyused weight-loss strategies in this study, $19 \%$ of the girls reported smoking, $15 \%$ inducing-vomiting, $5 \%$ using laxatives and $4 \%$ using diet pills as a means of weight control. Weight gain on smoking cessation is reportedly greater in women than in men (Flegal et al. 1995) which, due to their fear of fatness, carries serious implications for adolescent girls. Teenage girls fear the immediate possibility of gaining weight far more than the remote likelihood of serious disease and premature death from smoking-related illnesses, and cigarette companies have been blamed for shrewdly playing on this in their advertising campaigns (Califano, 1995). The increasing numbers of teenage girls who become regular smokers (Pierce et al. 1994) portends disastrous consequences for women's health. The link with smoking, therefore, represents the most overwhelming reason for urgent and effective action to address the issue of fear of fatness. 
The development of effective strategies which will protect adolescent girls from fear of fatness necessitates understanding their desire for thinness and its origins. It has been reported that dissatisfaction with body weight among pre-adolescent and young adolescent girls also extends to a dissatisfaction with their body shape (Hill et al. 1992). A recent study which included older adolescent girls and young women, found that weight concerns and dieting behaviour are influenced more by the degree to which their skeletal structure deviates from the 'thin-ankled, narrow-hipped' standard of female beauty that is currently in vogue, than by their degree of adiposity (Davis et al. 1993). These findings, if applicable to younger groups, indicate that the thinner, narrower shape which represents the goal of slimming adolescent girls, will remain elusive due to the fact that bone frame size is essentially resistant to change by diet or exercise.

'The ideal of female beauty may now be described as having an eating disorder.'

The origin of the desire for thinness is often referred back to the portrayal in the media of the ultra-slender female form as the epitome of beauty and sexual attractiveness. For example, a study of English fashion models over the years 1967-87 demonstrated that the desired shape for models was becoming more tubular with bust and hips decreasing while height and waist increased (Morris et al. 1989). A study of the body measurements of Playboy magazine centrefolds and Miss America contestants for 1979-88 indicated a body weight 13-19\% below the expected weight for women in that age-group (Wiseman et al. 1992). Considering that body weights below $15 \%$ the expected weight represent one of the criteria for diagnosis of anorexia nervosa, the authors conclude from this study that the ideal of female beauty may now be classified as having one of the major symptoms of an eating disorder (Wiseman et al. 1992). Although the media play an important role in promoting this ultra-thin ideal of female beauty, nonetheless, it is not involved in creating such an image but merely reflects what is socially and culturally accepted.

\section{SOCIAL, ECONOMIC AND PSYCHOLOGICAL ASPECTS OF OBESITY}

The most immediate consequences of overweight during adolescence are psychological (Must, 1996). The strong prejudice against obese children and adolescents within our society has been documented recently. In a British study involving 180 predominantly lean schoolchildren aged 4-11 years Wardle et al. (1995) described how professionally drawn pictures of fat children attracted more than $50 \%$ of all negative attributions with the exception of 'scared'; and no more than $22 \%$ of any positive attributions except for 'strong'. Fat children were thought of as ugly, lazy, stupid and selfish (Wardle et al. 1995). The fact that girls reach adolescence with such a clear impression of the contempt and rejection extended to overweight children provides some insight into their fatness phobia.

The reality of present day discrimination against overweight women is evident from the findings of a recent study undertaken in a nationally representative sample $(n 10039)$ of young Americans. This study examined the relationship between overweight (BMI $\geqslant 95$ th percentile for age and sex) in adolescents and young adults (age range 16-24 years) and their subsequent educational attainment, marital status and household income (Gortmaker et al. 1993). Furthermore, in this study these characteristics in overweight subjects were compared with those for young people with asthma, musculo-skeletal abnormalities, diabetes, epilepsy and other chronic physical conditions reported to cause limitations in work performance. After 7 years of follow-up, women who had been overweight at baseline were found to have completed less time at school $(P=0 \cdot 009)$, were less likely to 
be married $(P<0.001)$, had lower incomes $(P<0.001)$, and had higher rates of household poverty $(P<0.001)$ than women who had not been overweight; independent of their baseline socio-economic status and aptitude test scores (Gortmarker et al. 1993). The extent of this discrimination against overweight women is described by (a) the fact that the adolescents who reported having work-limiting, chronic conditions (excluding obesity) did not differ in these ways from the non-overweight subjects and (b) that the only significant finding for overweight men in this study was that they were less likely to be married $(P<0.005)$. Similar findings regarding the particular vulnerability of overweight women compared with men to a downward social spiral have been reported by British studies (Braddon et al. 1986; Sargent \& Blanchflower, 1995).

'Success at dealing with fear of fatness ultimately depends on how effectively the discrimination against overweight women is dealt with.'

These studies clearly demonstrate that the success of public health campaigns to address the fear of fatness issue among teenage girls will ultimately depend on how effectively the discrimination against overweight women is dealt with. Stunkard \& Sorenson (1993) have outlined how such action needs to begin with health professionals, many of whom have been shown to have negative attitudes towards obese people. Negative stereotypes of obesity appear to be related to the belief that the person can be blamed, or held responsible, for their own weight (Wooley, 1987). However, the frantic bulimic behaviours associated with weight-loss efforts by overweight women clearly indicate the lengths they are prepared to go to become slimmer (Serdula et al. 1993). Furthermore, there is now a well-established consensus that there are no easy answers to our lack of success in the treatment of obesity (National Institutes of Health, 1993).

\section{HEALTH RISKS ASSOCIATED WITH FATNESS DURING FEMALE ADOLESCENCE}

Although the health risks of obesity during female adulthood are recognized (Flynn \& Gibney, 1991), these risk associations during female adolescence are far less perceptible. This is partly due to logistical problems associated with the extended follow-up periods necessary for determination of the long-term outcomes of obesity in youth. Perhaps as the corollary to this, only a small number of studies exist to provide data on these outcomes for adolescent girls (Mossberg, 1989; Must et al. 1992; Nieto et al. 1992). Other reasons for the lack of clear information on the health consequences of female fatness during adolescence relate to the fact that the assessment of overweight during this period is complicated by the rapid growth that is a normal process of this developmental stage. In fact is has been stressed that a good knowledge of the normal patterns of growth and development is a prerequisite to any understanding of the 'abnormal' pattern of obesity (Johnson, 1985).

\section{Fatness, growth and maturational timing during female adolescence}

The intricacy of the relationship between overweight during female adolescence and patterns of growth and development is perhaps best illustrated by the consistent association of level of fatness, body size and menarcheal timing. It is well established that a particular value for fat : lean mass is normally necessary for menarche and the maintenance of regular ovulatory cycles (Frisch, 1985). Using data on approximately 17000 adult white women, aged 20-35 years, Garn et al. (1986) found that women who matured early (menarche at 
age 11 years or younger) were slightly shorter and significantly fatter than those maturing later (menarche at age 14 years or later). Furthermore, these differences in fatness were found to increase with age so that by age 30 years $26 \%$ of the 'early maturers' were obese compared with less than $15 \%$ of the 'late maturers'. The authors conclude that maturational timing probably has a greater long-term effect on the level of fatness than the level of fatness has on maturational timing (Garn et al. 1986).

Another aspect of this association concerns a possible link between overweight during female adolescence and the development of an abdominal type of body fat distribution which is associated with higher health risks of obesity. Baumgartner \& Roche (1988) investigated the development of body fat distribution in children aged 4-14 years and found that while no change in fat pattern was evident during childhood, a tendency toward an abdominal fat distribution occurred at the start of pubescence. This suggests that adolescence may be a critical developmental period for fat patterning. Deutsch et al. (1985) found, in a large cross-sectional sample of adolescents and young adults participating in the US Health Examination Survey, that the association evident between advanced maturation (determined by skeletal age) and abdominal body fat distribution in girls, disappeared after controlling for level of fatness (indicated by BMI). The authors concluded that obesity during adolescence may be a determinant of abdominal body fat distribution (Deutsch et al. 1985). More recently this was investigated using longitudinal data from the Amsterdam Growth and Health Study which examined rapidly-and slowly-maturing adolescents over a period of 14 years (van Lenthe et al. 1996). Using early menarche rather than skeletal age as a biological marker of maturity in girls, early maturation was significantly associated with an abdominal body fat distribution which persisted into adulthood. Controlling for level of fatness had no effect on this association, however, which indicates that advanced sexual maturation during adolescence, rather than obesity, seems to be the determinant of the development of an abdominal fat pattern (van Lenthe et al. 1996).

'Balancing the benefits of obesity prevention against the possible risks associated with growth retardation during puberty.'

These findings on the intricate relationship between timing of developmental stages, such as menarche, and female fatness during adolescence raises the possibility that weightcontrol intervention strategies aimed at this age-group may inadvertently compromise growth patterns. Dietz \& Hartung (1985) found that even mild energy intake restriction in obese girls ( $n$ 14, aged 2-12 years) led to significant reductions in height velocity, the magnitude of which appeared to be directly related to the amount of weight lost. The possible harmful consequences of this are indicated by the results of a long term (40-52 years of follow-up) study of children where it was found that the association between prepubertal growth velocity and mortality tended to be inverse, although this tendency was not statistically significant (Nieto et al. 1992). Evaluation of the health benefits of weightcontrol intervention strategies aimed at adolescent girls must, therefore, balance the benefits involved in the possible prevention of obesity against the long-term risks which may be associated with growth retardation during pubescence. In relation to obesity prevention, Hirsch et al. (1989) reminds us that although puberty is the only time apart from infancy during which fat cells appear in great numbers, the effects of dietary intervention on human cellularity remain unknown. In summary, because of the rapid growth and development that occurs during the pubertal growth spurt, the detection, evaluation and treatment of overweight during adolescence is extremely complex. 


\section{Short-term health consequences of female fatness during adolescence}

Although there are childhood cases involving serious complications of obesity, such as obstructive apnoea, cardiomyopathy and pancreatitis (Taitz, 1983), these are very rare and are largely restricted to the severely obese. Obesity during adolescence, however, is also associated with a higher cardiovascular disease risk profile which is of greater concern due to the strength of the association between cardiovascular disease and adult obesity (Lew \& Garfinkel, 1979). With respect to adolescent girls there is evidence that overweight and fatness are significantly associated with current levels and changes in hypertension (Stallones et al. 1982), blood lipids and lipoproteins (Freedman et al. 1989) and plasma insulin (Freedman et al. 1987). Using the prevalence of these risk factors to assess the health consequences of female fatness during adolescence, however, involves the assumption that adolescent status, regarding both overweight and associated risk factors, will continue until and throughout adulthood.

In support of such assumptions there is evidence that some risk factors, among them serum cholesterol and lipoprotein subfractions, may become established in children and track through adolescence into adulthood (Webber et al. 1991). Furthermore, it has been reported that obesity acquired during adolescence and early adulthood has deleterious effects on adult cholesterol levels and lipoprotein subfractions (Laurer et al. 1988). However, these effects of obesity were (a) generally more apparent in males than in females, and (b) more related in females to increasing obesity during young adulthood than during adolescence (Laurer et al. 1988). With respect to serum lipids in particular, the risk of subsequent development of cardiovascular disease is more questionable in females compared with males (Hulley et al. 1992; Jacobs et al. 1992) and these gender differences have been cited as a major problem in a recent criticism (Newman et al. 1995) of the recommendations for selective screening for, and treatment of, childhood hypercholesterolaemia (National Cholesterol Education Program, 1992). Finally, although atherogenic lipids have been quantitatively linked with the extent of fatty streaks in the aorta of children and adolescents (mean age 18 years) dying in accidents, this finding was much weaker in females compared with males and was unrelated to obesity during childhood and adolescence (Newman et al. 1986).

\section{Long-term health consequences of female fatness during adolescence}

Definitive information on the translation into disease of these associations between cardiovascular disease risk factors and female fatness during adolescence can only be derived from long-term morbidity and mortality studies. In a 40-year follow-up study Mossberg (1989) found excessive obesity during female adolescence to be associated with higher than expected morbidity and mortality. The most common cause of these outcomes was cardiovascular disease, but weight during adulthood was also found to contribute to these endpoints. The subjects ( $n$ 504) in this study were, however, a 'special' population in that (a) they were recruited from children (0-16 years) who were admitted to Swedish hospitals for obesity treatment, and (b) included children with Frohlich's disease (9\%) and obesity secondary to cerebral palsy $(7 \%)$ whom follow-up found to be more vulnerable to chronic disease (Mossberg, 1989).

Long-term studies have also been undertaken in community-based populations to determine the health consequences of female fatness during adolescence. Nieto $e t$ al. (1992) report on a follow-up study of mortality according to weight and growth variables when subjects were 5-18 years old; the time between earliest measurements and the end of follow-up was 52 years. Among the $46 \%$ of subjects for whom follow-up data were 
available ( $n 1351$ females), all-cause mortality was significantly elevated for females in the top quintile of relative weight during adolescence compared with those in the lowest quintile. It was recently pointed out, however, that the internally-derived $\mathrm{z}$ score (relative weight expressed in SD units) used in this study as the index of relative weight, makes it difficult to evaluate the amount of weight that was associated with this increase in mortality (Must, 1996). Moreover, it has been estimated that the top quintile corresponds to a relative weight of only $106 \%$, which suggests that there were few overweight youths in the sample (Anonymous, 1993).

\section{'Chronic obesity $v$. 'puppy fat'.'}

A further limitation of this study acknowledged by the authors (Nieto et al. 1992) concerns the unavailability of data on adult relative weight because it is possible that adult weight, which is associated with childhood weight (Johnson, 1985), may explain all the variability between overweight during adolescence and adult female mortality. Support for this possibility is evident in the recent report on coronary disease risk from the Nurse's Health Study which included data on 115818 women (Willett et al. 1995). This 14-year follow-up study found that when BMI at 18 years of age and BMI during middle age at baseline (30-55 years) were included in the same multivariate model, the significant positive relationship between BMI during middle age and coronary disease remained essentially unchanged, whereas virtually no relationship remained for BMI at 18 years of age (the relative risk of coronary disease for women in the highest relative weight quintile $\left(B M I>23 \mathrm{~kg} / \mathrm{m}^{2}\right)$ at 18 years of age, compared with those in the lowest (BMI $<19 \mathrm{~kg} / \mathrm{m}^{2}$ ) was $1.05(95 \% \mathrm{Cl} 0.85-1.29))$. These findings indicate that it is important when determining the health consequences of female fatness during adolescence to distinguish between those girls who are truly developing chronic obesity and those who are temporarily fat i.e. 'puppy fat'.

The only other study of the long-term effects of overweight during female adolescence did; however, control for adult weight status (Must et al. 1992). This report from the Harvard Growth Study compared morbidity and mortality over 55 years of follow-up in men $(n 256)$ and in women $(n$ 252) who had been consistently lean (BMI $>25$ th $<50$ th percentiles of a large US national survey) and consistently overweight (BMI $>75$ th percentile) during adolescence. No increase in the relative risk of death from all causes or cause-specific death was found among women according to weight category in adolescence (Must et al. 1992). Furthermore these findings were not altered by control for adult weight status, although such control weakened the significant relationship between overweight during male adolescence and mortality. In fact the only significant health risks that could be identified in this study for female fatness during adolescence consisted of a higher incidence of arthritis and of reporting difficulties in the performance of activities of daily living (Must et al. 1992).

\section{Level of fatness during female adolescence and obesity during adulthood}

The results of these long-term studies, however variable, indicate the importance of determining how accurately overweight during female adolescence predicts obesity during adulthood. In a nationally-representative cohort study $(n 10039)$ of American adolescents and young adults (16-24 years), Gortmaker et al. (1993) reported that after a 7 year followup period there were fewer females compared with males $(66 v .70 \%)$ remaining overweight. Similar findings were reported by Guo et al. (1994) who found that overweight 
status persisted to age 35 years in $66 \%$ of women compared with $78 \%$ of men who were overweight at age 18 years (BMI $\geq 95$ th percentile).

A recent examination of the tracking of BMI over a 50-year period in a longitudinal study ( $n 67$ boys and $n 67$ girls) reported that the prediction of ponderosity in middle age from BMI during childhood and adolescence is more reliable for males than for females (Casey et al. 1992). Overall, the tracking of body size from childhood to middle age was found to be poor for females, improving slightly after adolescence. This is in agreement with the findings of Cronk et al. (1982) whose results indicate that for both men and women, influences beginning after adolescence have a greater effect on body fatness in adulthood. Further support for the hypothesis that early adulthood may be a more critical period than adolescence for the development of chronic female obesity is evident from the findings of Braddon et al. (1986) who tested the predictive value of childhood obesity in adult life. Using a large UK national cohort of children ( $n$ 3322) who were studied from birth to 36 years, these workers found that only $30 \%$ of obese adult women were obese during childhood and/or adolescence and that the remaining $70 \%$ first became obese during early adulthood (Braddon et al. 1986).

In summary: prevention of adult female obesity through intervention strategies aimed at overweight adolescent girls will miss approximately $70 \%$ of those at risk (who remain 'hidden' within normal weight categories), while one-third of those targeted may only be 'puppy fat' and not at risk of chronic obesity.

\section{OVERWEIGHT PREVALENCE AND TRENDS: IMPLICATIONS FOR OBESITY-PREVENTION PROGRAMMES AIMED AT FEMALE ADOLESCENTS}

The recent reports describing increasing trends in the prevalence of adult obesity, particularly in the decade from 1980 to 1990 , emphasize the need for preventative strategies. Women seem to be particularly vulnerable to this 'fattening' trend and surpass men in terms of the proportions defined as obese in the UK study ( $15 v .12 \%$ for women and men having $\mathrm{BMI}>30 \mathrm{~kg} / \mathrm{m}^{2}$ respectively; Bennett et al. 1995); while US data (Kuczmarski et al. 1994) show black women to be most at risk; over $49 \%$ of them are clinically overweight (BMI $\left.>27.3 \mathrm{~kg} / \mathrm{m}^{2}\right)$.

For American children (aged 6-11 years) and adolescents (aged 12-17 years) Troiano et al. (1995) recently reported similar increases in overweight prevalence and trends during the same period (1980-91). Furthermore, black female adolescents were reported to be among those experiencing the greatest increase in overweight prevalence (now approximately $14.4 \%$ have a $\mathrm{BMI} \geqslant 95$ th percentile cut-off), while the lowest increase was found for white female adolescents (currently $8.4 \%$ have a BMI $\geqslant 95$ th percentile). These data suggest that precursors of the differences in overweight prevalence among race-ethnic groups seen among adults (Kuczmarski et al. 1994) may be observed among adolescents. Such race-ethnic associations also reflect the higher prevalence of female obesity evident among those of low income and educational level (Braddon et al. 1986; Flegal et al. 1988).

\section{Screening adolescents for risk of obesity}

Overweight is notoriously difficult to treat and is now recognized as a chronic condition which requires long-term treatment and follow-up (National Institutes of Health, 1993). Consequently, the recent large (and possibly continuing) increases in the prevalence of this refractory condition are considered by many to be clear indications of the need for greater 
vigilance in the use of weight-control strategies to prevent the development of obesity during childhood and adolescence (Kuczmarski et al. 1994). A recent development in this area was the publication of recommendations for screening for overweight during adolescence (Himes \& Dietz, 1994). According to these expert committee guidelines, youths with a BMI $\geqslant 95$ th percentile for age and sex, or BMI $>30 \mathrm{~kg} / \mathrm{m}^{2}$, should be considered overweight and referred for in-depth medical follow-up to exclude obesityrelated health problems. In addition, adolescents with a BMI $>85$ th percentile but $<95$ th percentile should be considered 'at risk' of overweight and referred to a second level screen to determine risk of development of obesity and associated health problems.

There are, however, several reasons why such screening programmes may be premature and, furthermore, why a BMI $>95$ th percentile should be the only criterion for the definition of overweight risk during adolescence. Of these, the difficulties in defining overweight for youths need to be considered (Troiano et al. 1995). Overweight should reflect adiposity and be related to morbidity and mortality outcomes and as yet there is no clear consensus on what the definition of overweight during adolescence should be (Troiano et al. 1995). Although the use of a definition based on BMI is desirable because weight and height measurements are easily obtained, nonetheless BMI is not as reliable a measure of fatness for children as for adults who have reached their peak height. The BMI changes dramatically with age during childhood and adolescence (Siervogel et al. 1991); therefore, a given BMI has very different implications for body composition depending on age. For example, the BMI value for overweight (95th percentile) in girls aged 10 years compared with girls aged 17 years is 23 and 30 respectively. Although the overweight criterion recommended by the expert committee is age- and sex-specific (Himes \& Dietz, 1994), this cannot account for biological differences of 2-4 years which can be expected in any two adolescent girls of exactly the same chronological age due to variation in maturational timing.

Further reasons for caution when using the BMI to assess adolescents, however, relate to the changes that occur throughout youth in the components contributing to the composite measure of BMI. During growth and maturity, body proportions, bone mass and lean : fat tissue change at different times and different rates. The timing of these body composition changes may, as discussed previously, be related to the development of overweight and obesity (Garn et al. 1986; van Lenthe et al. 1996).

Another aspect of growth during the adolescent period which confounds the assessment of overweight concerns the possibility that weight may normalize in the absence of weight loss (Must, 1996). Estimates that 1-2 years of weight maintenance are required for each $20 \%$ increment in excess ideal weight (Dietz \& Robinson, 1993) suggest that a weight-loss prescription may be avoided when overweight is not extreme (Must, 1996).

'I'd do anything (dieting, fasting, smoking, purging etc.) to avoid being fat....'

Finally the formal characterization of adolescents into 'at risk' groups (i.e. those with BMI $>85$ th percentile but $<95$ th percentile) without careful follow-up to counsel those stigmatized by such a label, may increase the incidence of eating disorders and unhealthy food-related behaviours through fear of fatness. In the light of these potential adverse outcomes and considering the limitations of the BMI to assess adiposity during adolescence, there is support for moderating the approach of the expert committee (Himes \& Dietz, 1994) by using BMI > 95th percentile (or BMI $>30 \mathrm{~kg} / \mathrm{m}^{2}$ ) as the only criterion of overweight and, thus, omitting the 'at risk' group (Troiano et al. 1995). In fact it was 
recently concluded that 'until we have solid data on the health effects of different weights and weight change, the need to protect adolescents from undue pressure to lose weight is paramount and should preclude an emphasis on specific weight targets' (Must, 1996).

\section{Treatment of obesity during adolescence}

The decision to screen for overweight during adolescence will, however, ultimately depend on the availability of resources to cover the high cost of treatment for this group. Due to the rapid growth and development that occurs during adolescence, there are several essential components to weight control programmes for youths identified as overweight by BMI $\geqslant 95$ th percentile. Apart from counselling to deal with the issue of fear of fatness, these include carefully-planned dietary advice to ensure that high nutritional requirements are being met, and frequent monitoring in the long term to ensure growth velocity is not compromised. Epstein et al. (1990) have shown that such individualized treatment of childhood obesity from pre-adolescence through to young adulthood can be effective without compromising growth. This successful programme included parental involvement in addition to individualized behaviour therapy for dietary and exercise modification. While these results suggest a possible approach for adolescents within intact families, it is obvious that such intensive treatment can only be made available to very limited numbers.

\section{CONCLUSIONS}

Fear of fatness is pervasive among adolescent girls and is associated with many unhealthy behaviours which carry serious long-term health risks, e.g. smoking. Reasons for this phobia almost certainly include the intense stigmatization of female obesity and the discrimination against overweight women in developed societies. Effective intervention to correct this is urgently needed.

Given their fear of fatness, care must be taken to protect adolescent girls from any additional pressure to lose weight. Considering all the issues discussed in the present paper, including the probability that weight-control intervention in overweight adolescent girls has little impact on the prevalence of female adult obesity, it would appear that preventative measures after the adolescent period would be safer and more effective. Indeed, the sensitive nature of the adolescent period in terms of growth and development and its intricate links with body fatness, emphasize our lack of knowledge of the long-term health implications of weight-control intervention in this group. Finally, further support for delaying obesity intervention programmes until after adolescence is provided by current data which indicate that the health risks conferred by fatness during female adolescence are primarily those associated with the persistence of overweight status into middle age.

The identification of adolescence as the period during which physical activity declines, particularly among girls, (Heath et al. 1994), provides clues on what may represent the most appropriate intervention strategy to prevent the development of obesity for this age group. The role of physical activity in the prevention of overweight and obesity is well recognized (Wilmore, 1996). With respect to adolescent girls, however, the possibility that modern inactive lifestyles may be of greater significance than diet in the aetiology of obesity (Prentice \& Jebb, 1995), indicates that this type of intervention may also be the most effective. In support of this approach Must (1996) recently concluded that: 'a focus on the prevention of childhood and adolescent obesity through increased physical activity, decreased sedentary activity, and better food choice offers the best opportunity to optimise health and longevity'. 


\section{REFERENCES}

Anonymous (1993). Summary of the Workshop on Child and Adolescent Obesity: what, how, and who? Critical Reviews in Food Science and Nutrition 33, 287-305.

Baumgartner, R. N. \& Roche, A. F. (1988). Tracking of fat pattern indices in childhood: the Melbourne Growth and Health Study. Human Biology 60, 549-567.

Bennett, N., Doda, T., Flatley, J., Freeth, S. \& Bolling, K. (1995). Health Survey for England 1993. London: H.M. Stationery Office.

Braddon, F. E. M., Rodgers, B., Wadsworth, M. E. J. \& Davies, J. M. C. (1986). Onset of obesity in a 36 year birth cohort study. British Medical Joumal 293, 299-303.

Califano, J. A. (1995). The wrong way to slim. New England Journal of Medicine 333, 1214-1216.

Casey, V. A., Dwyer, J. T., Coleman, K. A. \& Valachan, I. (1992). Body mass index from childhood to middle age: a 50-y follow-up. American Journal of Clinical Nutrition 56, 14-18.

Crawley, H. F. \& Shergill-Bonner, R. (1995). The nutrient and food intakes of 16-17 year old female dieters in the UK. Journal of Human Nutrition and Dietetics 8, 25-34.

Cronk, C. E., Chumlea, W. L. \& Kent, R. (1982). Longitudinal trends of weight/stature ${ }^{2}$ in childhood in relation to adulthood body fat measures. Human Biology 54, 751-754.

Davis, C., Durnin, J. V. G. A., Le Maire, A. \& Dionne, M. (1993). Body composition correlates of weight dissatisfaction and dietary restraint in young women. Appetite 20, 197-207.

Deutsch, M. I., Mueller, W. H. \& Malina, R. M. (1985). Androgyny in fat patterning is associated with obesity in adolescents and young adults. Annals of Human Biology 12, 275-286.

Dietz, W. H. \& Hartung, R. (1985). Changes in height velocity of obese pre-adolescents during weight reduction. American Journal of Diseases of Childhood 139, 705-707.

Dietz, W. H. \& Robinson, T. N. (1993). Assessment and treatment of childhood obesity. Paediatrics Reviews 14, 337-343.

Epstein, L. H., Valoski, A., Wing, R. R. \& McCurley, J. (1990). Ten year follow-up of behavioural, family-based treatment for obese children. Journal of the American Medical Association 264, 2519-2523.

Flegal, K. M., Harlan, W. R. \& Landis, J. R. (1988). Secular trends in body mass index and skinfold thickness with socio-economic factors in young women. American Journal of Clinical Nutrition 48, 535-543.

Flegal, K. M., Troiano, R. P., Pamuk, E. R., Kuczmarski, R. J. \& Campbell, S. M. (1995). The influence of smoking on the prevalence of overweight in the United States. New England Journal of Medicine 333, 11651170.

Flynn, M. A. T. \& Gibney, M. J. (1991). Obesity and health: why slim? Proceedings of the Nutrition Society 50, 413-432.

Fox, M. (1991). Adolescent attitudes towards body physique. Proceedings of the Nutrition Society 50, 115A.

Freedman, D. S., Srinivasan, S. R., Burke, G. L., Shear, C. L., Smoak, C. G., Harsha, D. W., Webber, L. S. \& Berenson, G. S. (1987). Relation of body fat distribution to hyperinsulinemia in children and adolescents: the Bogalusa Heart Study. American Journal of Clinical Nutrition 46, 403-410.

Freedman, D. S., Srinivasan, S. R., Harsha, D. W., Webber, L. S. \& Berenson, G. S. (1989). Relation of body fat patterning to lipid and lipoprotein concentrations in children and adolescents: the Bogalusa Heart Study. American Joumal of Clinical Nutrition 50, 930-939.

Frisch, R. E. (1985). Fatness, menarche and female fertility. Perspectives in Biology and Medicine 28, 611-633.

Garn, S. M., Lavelle, M., Rosenberg, K. R. \& Hawthorne, V. M. (1986). Maturational timing as a factor in female fatness and obesity. American Journal of Clinical Nutrition 43, 879-883.

Gortmaker, S. L., Must, A., Perrin, J. M., Sobol, A. M. \& Dietz, W. H. (1993). Social and economic consequences of overweight in adolescence and young adulthood. New England Journal of Medicine 329, 1008-1012.

Guo, S. S., Roche, A. F., Chumlea, W. C., Gardner, J. D. \& Siervogel, R. M. (1994). The predictive value of childhood body mass index values for overweight at age 35 y. American Journal of Clinical Nutrition 59, 810-819.

Heath, G. W., Pratt, M., Warren, C. W. \& Kann, L. (1994). Physical activity patterns in American High School students. Archives of Pediatric and Adolescent Medicine 148, 1131-1136.

Hill, A. J. (1993a). Pre-adolescent dieting: implications for eating disorders. International Review of Psychiatry $5,87-100$.

Hill, A. J. (1993b). Causes and consequences of dieting and anorexia. Proceedings of the Nutrition Society 52, 211-218.

Hill, A. J., Draper, E. \& Stack, J. (1994). A weight on children's minds; body shape dissatisfaction at 9 years old. International Journal of Obesity 18, 383-389.

Hill, A. J., Oliver, S. \& Rogers, P. J. (1992). Eating in the adult world: the rise of dieting in childhood and adolescence. British Journal of Psychology 31, 95-105.

Himes, J. H. \& Dietz, W. H. (1994). Guidelines for overweight in adolescent preventive services: recommendations from an expert committee. American Joumal of Clinical Nutrition 59, 307-316. 
Hirsch, J., Fried, S. K., Edens, N. K. \& Liebel, R. L. (1989). The fat cell. Medical Clinics of North America 73, 83-96.

Hoey, H., Tanner, J. M. \& Cox, L. A. (1986). Irish Clinical Growth Standards, Girls: Birth - 19 Years, Height and Weight. Ware, Herts.: Castlemead Publications.

Hulley, S. B., Walsh, J. M. \& Newman, T. B. (1992). Health policy on blood cholesterol: time to change directions. Circulation 86, 1026-1029.

Jacobs, D., Blackburn, H., Higgins, M., Reed, D., Iso, H., McMillan, G., Neaton, J., Nelson, J., Potter, J., Rifkind, B., Rossouw, J., Shekelle, R. \& Yusuf, S. for participants in the Conference on Low Blood Cholesterol: Mortality Associations (1992). Report of the Conference on Low Blood Cholesterol: Mortality Associations. Circulation 86, 1046-1060.

Johnson, F. E. (1985). Health implications of childhood obesity. Annals of Internal Medicine 103, $1068-1072$.

Killen, J. D., Barr Taylor, C., Telch, M. C., Saylor, K. E., Maron, D. J. \& Robinson, T. N. (1986). Self-induced vomiting and laxative use among teenagers. Joumal of the American Medical Association 255, 1447-1449.

Kuczmarski, R. J., Flegal, K. M., Campbell, S. M. \& Johnson, C. L. (1994). Increasing prevalence of overweight among US adults. Journal of the American Medical Association 272, 205-211.

Laurer, R. M., Lee, J. \& Clarke, W. R. (1988). Factors affecting the relationship between childhood and adult cholesterol levels: the Muscatine Study. Paediatrics 82, 309-318.

Lew, E. A. \& Garfinkel, L. (1979). Variations in mortality by weight among 750,000 men and women. Journal of Chronic Disease 32, 563-576.

Lucas, A. R. (1983). Undernutrition and growth. New England Joumal of Medicine 309, 550-551.

Maloney, M. J., McGuire, J., Daniels, S. R. \& Specker, B. (1989). Dieting behaviour and eating attitudes in children. Paediatrics 84, 482-489.

Matkovic, V. (1991). Calcium metabolism and calcium requirements during skeletal modelling and consolidation of bone mass. American Journal of Clinical Nutrition 54, 245S-260S.

Morris, A., Cooper, T. \& Cooper, P. J. (1989). The changing shape of female fashion models. International Journal of Eating Disorders 8, 593-596.

Moses, N., Banlivy, M.-N. \& Lifshitz, F. (1989). Fear of obesity among adolescent girls. Pediatrics 83, 393398.

Mossberg, H. O. (1989). 40-year follow-up of overweight children. Lancet ii, 491-493.

Must, A. (1996). Morbidity and mortality associated with elevated body weight in children and adolescents. American Journal of Clinical Nutrition 63, 445S-447S.

Must, A., Jacques, P. F., Dallal, G. E., Bajema, C. J. \& Dietz, W. H. (1992). Long term morbidity and mortality of overweight adolescents: a follow-up study of the Harvard Growth Study of 1922 to 1935. New England Journal of Medicine 327, 1350-1355.

National Cholesterol Education Program (1992). Report of the Expert Panel on Blood Cholesterol Levels in Children and Adolescents. Pediatrics 89, 515-584.

National Institutes of Health (1993). Methods for voluntary weight loss and control: NIH Technology Assessment Conference Statement. Annals of Internal Medicine 119, 764-770.

National Institutes of Health (1994). Consensus Development Panel on Optimal Calcium Intake. Journal of the American Medical Association 272, 1942-1948.

Newman, T. B., Garber, A. M., Holtzmann, A. \& Hulley, S. B. (1995). Problems with the Expert Panel on Blood Cholesterol Levels in Children and Adolescents. Archives of Pediatric and Adolescent Medicine 149, 241-247.

Newman, W. P., Friedman, D. S., Voors, A. W., Gard, P. D., Srinivasan, S. R., Cresanta, J. L., Williamson, G. D., Webber, L. S. \& Berenson, G. S. (1986). Relation of serum lipoprotein levels and systolic blood pressure to early athersclerosis. New England Journal of Medicine 314, 138-144.

Nieto, F. J., Szklo, M. \& Comstock, G. W. (1992). Childhood weight and growth rate as predictors of adult mortality. American Journal of Epidemiology 136, 201-213.

Patton, G. C., Johnson-Sabine, E., Wood, K., Mann, A. H. \& Wakeling, A. (1990). Abnormal eating attitudes in London schoolgirls - a prospective epiderniological study: outcome at twelve month follow-up. Psychological Medicine 20, 382-394.

Pierce, J. P., Lee, L. \& Gilpin, E. A. (1994). Smoking initiation by adolescent girls, 1944 through 1988. Journal of the American Medical Association 271, 608-611.

Prentice, A. M. \& Jebb, S. A. (1995). Obesity in Britain: gluttony or sloth? British Medical Journal 311, 437439.

Pugliese, M. T., Lifshitz, F., Grad, G., Fort, P. \& Marks-Katz, M. (1983). Fear of obesity: a cause of short stature and delayed puberty. New England Journal of Medicine 309, 513-518.

Ryan, Y., Gibney, M. J., Johnson, H. \& Flynn, M. A. T. (1997). Weight perceptions and weight loss practices of Irish teenage girls. Proceedings of the Nutrition Society 56, 48A.

Sargent, J. D. \& Blanchflower, D. G. (1995). Obesity and stature in adolescence and earnings in young adulthood. Archives of Pediatric and Adolescent Medicine 148, 681-687.

Serdula, M. K., Collins, M. E., Williamson, D. F., Anda, R. F., Pamuk, E. \& Byers, T. E. (1993). Weight control practices of US adolescents and adults. Annals of Internal Medicine 119, 667-671. 
Siervogel, R. M., Roche, A. E., Guo, S., Mukharjee, D. \& Chumlea, W. C. (1991). Patterns of change in weight/ stature $^{2}$ from 2 to 18 years: findings from long term serial data for children in the Fels Longitudinal Growth Study. International Journal of Obesity 15, 479-485.

Stallones, L., Mueller, W. H. \& Christensen, B. L. (1982). Blood pressure, fatness, and fat patterning among USA adolescents from two ethnic groups. Hypertension 4, 483-486.

Stunkard, A. J. \& Sorensen, T. I. A. (1993). Obesity and socio-economic status - a complex relation. New England Journal of Medicine 329, 1036-1037.

Taitz, L. S. (1983). The Obese Child, pp. 164-188. Boston, Mass : Blackwell Scientific Publications.

Troiano, R. P., Flegal, K. M., Kuczmarski, R. J., Campbell, S. M. \& Johnson, C. L. (1995). Overweight prevalence and trends for children and adolescents. Archives of Pediatric and Adolescent Medicine 149, 10851091.

Van Lenthe, F. J., Kemper, H. C. G., Van Mechelen, W., Post, G. B., Twisk, J. W. R., Welten, D. C. \& Snel, J. (1996). Biological maturation and the distribution of subcutaneous fat from adolescence into adulthood: the Amsterdam Growth and Health Study. International Joumal of Obesity 20, 121-129.

Wadden, T. A., Foster, G. D., Stunkard, A. J. \& Linowitz, J. R. (1989). Dissatisfaction with weight and figure in obese girls: discontent but not depression. International Journal of Obesity 13, 89-97.

Wardle, J., Volz, C. \& Golding, C. (1995). Social variation in attitudes to obesity in children. International Journal of Obesity 19, 562-569.

Webber, L. S., Srinivasan, S. R., Wattigney, W. A. \& Berenson, G. S. (1991). Tracking of serum lipids and lipoproteins from childhood to adulthood: the Bogalusa Heart Study. American Journal of Epidemiology 133, 884-899.

Whitaker, A., Davies, M., Shaffer, D., Johnson, J., Abrams, S., Walsh, B. T. \& Kalikow, K. (1989). The struggle to be thin: a survey of anorexic and bulimic symptoms in a non-referred adolescent population. Psychological Medicine 19, 143-163.

Willett, W. C., Manson, J. E., Stampfer, M. J., Colditz, G. A., Rosner, B., Speizer, F. E. \& Hennekens, C. H. (1995). Weight, weight change and coronary heart disease in women. Risk within the 'normal' weight range. Journal of the American Medical Association 273, 461-465.

Wilmore, J. H. (1996). Increasing physical activity. American Journal of Clinical Nutrition 63, 456S-460S.

Wiseman, C. V., Gray, J. J., Mosimann, J. E. \& Ahrens, A. H. (1992). Cultural expectations of thinness in women: an update. International Journal of Eating Disorders 11, 85-89.

Wooley, S. C. (1987). Psychological and social aspects of obesity. In Body Weight Control - the Physiology, Clinical Treatment and Prevention of Obesity, pp. 81-89 [A. E. Bender and L. J. Brooks, editors]. Melbourne and New York: Churchill Livingstone. 